\author{
United States Department of the Interior \\ Geological Survey
}

\title{
The Geophysical Expression of Selected Mineral Deposit Models
}

D.B. Hoover, W.D. Heran, and P.L. Hill, E ditors

\section{Open-File R eport 92-557 \\ 1992}

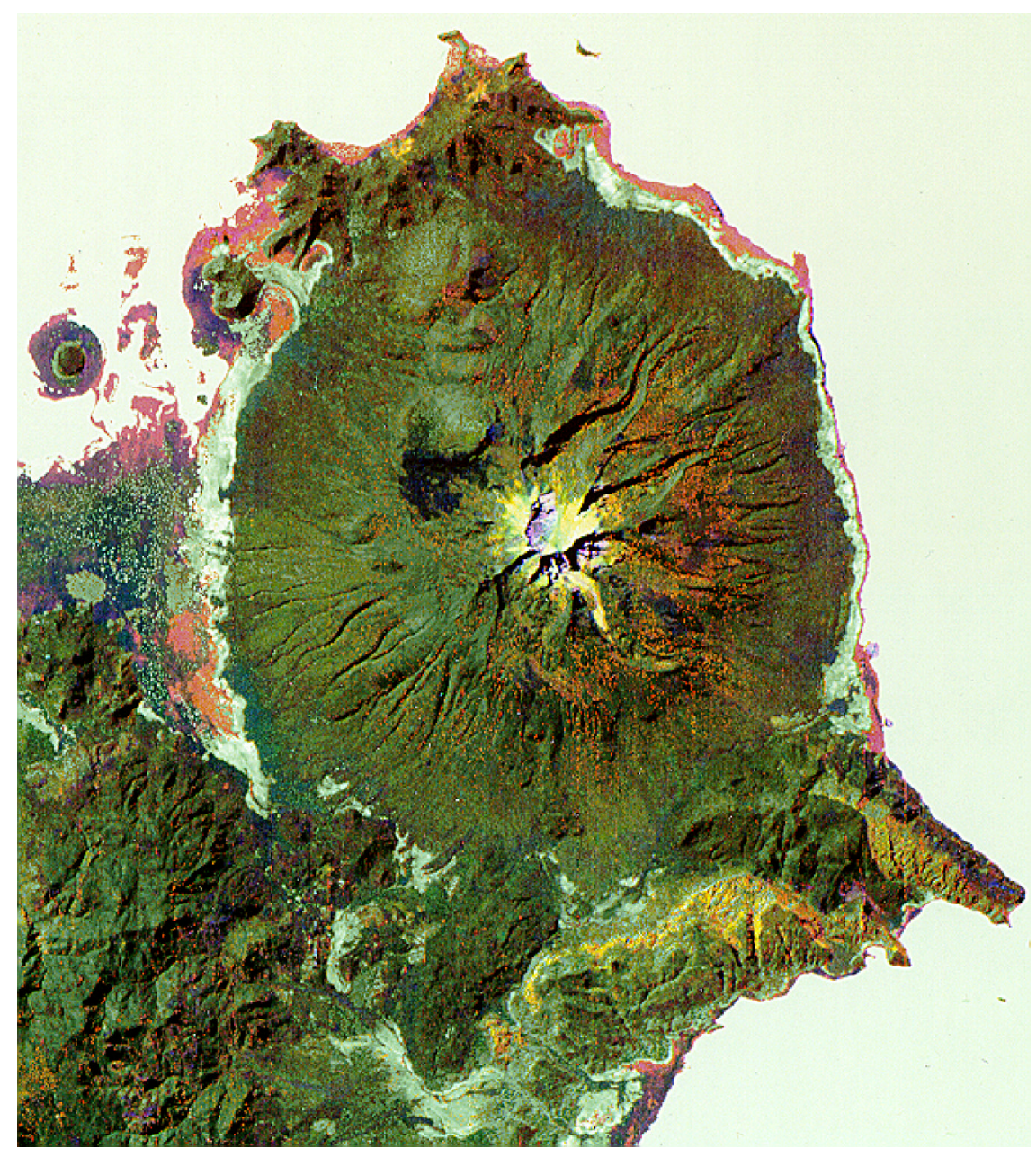


Cover: An example of remote sensing applied to mineral exploration LANDSAT TM Image, Color Ratio Composite, Bands 5/7, 3/1, 3/4 Volcanic form in the Altiplano high plains of Bolivia showing hydrothermal alteration patterns as determined by spectralreflectance characteristics of the surface derived from measurements made by the Thematic Mapper (TM) systems on LANDSATS 4 and 5 .

Resultant color ratios of channels:

Reds--clays and carbonate

Greens--iron oxide (limonite)

Yellows--mix

Knepper, D.H., and Simpson, S.L., 1992, Geology and mineral resources of the Altiplano and Cordillera Occidental, Bolivia: U.S. Geological Survey Bulletin 1975, p. 46-55. 